Research Article

\title{
Growth, Water Relations, and Photosynthetic Activity Are Associated with Evaluating Salinity Stress Tolerance of Wheat Cultivars
}

\begin{abstract}
Abeer Hamdy Elhakem
Department of Biology, College of Sciences and Humanities in AlKharj, Prince Sattam Bin Abdulaziz University, Alkharj 11942, Saudi Arabia
\end{abstract}

Correspondence should be addressed to Abeer Hamdy Elhakem; abeer_hamdy24@yahoo.com

Received 3 August 2020; Revised 19 September 2020; Accepted 24 September 2020; Published 29 October 2020

Academic Editor: Wei Wu

Copyright (c) 2020 Abeer Hamdy Elhakem. This is an open access article distributed under the Creative Commons Attribution License, which permits unrestricted use, distribution, and reproduction in any medium, provided the original work is properly cited.

\begin{abstract}
Salinity stress riskiness adversely affects the population by causing food and environmental issues. Moreover, the destructive impacts of salinization differ among various plant cultivars. In the present study, we evaluate the salt stress tolerance among three wheat cultivars based on growth criteria, leaf relative water content (LRWC), and abscisic acid (ABA) level by treating the plants with $0,40,80$, or $160 \mathrm{mM} \mathrm{NaCl}$. The results revealed that an increase in $\mathrm{NaCl}$ concentration caused a massive reduction in growth (shoot and root growth criteria and flag leaf area), photosynthetic pigments (chlorophyll a, chlorophyll b, carotenoids, and total pigments), and LRWC value, but a significant increase in the ABA content in flag leaf in all wheat cultivars. The wheat cultivars were otherwise exposed to anatomical characteristics and photosynthetic gas exchange investigations. $\mathrm{NaCl}$ toxicity induced a noticeable reduction in stomatal aperture area (SAA), stomatal conductance (Gs), transpiration rate (Tr), and leaf net photosynthetic rate $(\mathrm{Pn})$. These impacts were remarkable with the $160 \mathrm{mM} \mathrm{NaCl}$ treatments for all evaluated parameters. Moreover, Sakha 69 revealed salinity tolerance greater than Giza168, and Sakha8 was the most salt-sensitive cultivar. Consequently, we recognized Sakha 69 as a salt-tolerant cultivar that may be used as parents in breeding programs for new cultivars with enhanced salt tolerance and for further genetic investigations to reveal the genetic strategies controlling the response of salinity stress in the wheat plant.
\end{abstract}

\section{Introduction}

Salinity stress is one of the major environmental issues restricting the crop growth and productivity in arid and semiarid regions. The land area influenced by salinization is continuously increasing day by day [1]. Salinity can cause oxidative stress followed by ionic toxicity and osmotic pressure at the subcellular level [2]. Additionally, an increase in $\mathrm{NaCl}$ level in the plant cells around stomatal guard cells can cause stomatal closure [3], which decreases the availability of $\mathrm{CO}_{2}$, necessary for carbon fixation in the leaves, while also exposing chloroplasts to high excitation energy leading to the increase in reactive oxygen species which can lead to the death of cells [4].
There are various morphophysiological criteria such as growth parameters, plant-water relations, photosynthetic gas exchange properties, and pigment contents that are useful to detect the plant's physiological status under saline conditions. These criteria provide valuable information that can be used in evaluating the salt tolerance of genotypes in a breeding program, understanding the salt tolerance mechanisms, and supporting the crops and production under salt stress conditions by applying appreciating agronomic practices [5]. In addition, salt stress restricts the photosynthesis process by influencing the organelles' ultrastructure and concentration of metabolites and various pigments by suppressing several metabolic and physiological processes $[6,7]$. 
Abscisic acid (ABA) is a significant phytohormone that can regulate growth and development of plants as well as the response of stresses. It plays an important role in the stomatal closure by regulating ion fluxes of guard cells. Stomatal closure is the major process controlling the transpirational water loss of plants. Hence, ABA influences the pore size of stomata by both $\mathrm{Ca}^{2+}$-dependent and $\mathrm{Ca}^{2+}$ independent pathways [8]. Moreover, it was reported that there was a variation in ABA levels in the guard cells and roots after exposure to various treatments of $\mathrm{NaCl}$ stress [9].

Wheat (Triticum aestivum L.) belongs to the Poaceae family and is cultivated widely in most areas in the world [2]; moreover, its kernels are utilized in essential foods and noodles, and its straw is used as animal fodder as well as in the paper industry [10]. The annual world production of wheat is about 763.3 million metric tons [11]; however, it suffers considerable loss of grain yield due to salinization. While there are various strategies to enhance wheat production in salt-influenced regions, such as drainage or leaching, the cultivation of salt-tolerant cultivars is identified as the most beneficial strategy to overcome these restrictions [12]. This study aims to investigate the variations between salt-tolerant "Sakha 69," salt-moderate "Giza168," and saltsensitive "Sakha8" wheat cultivars regarding growth, water relations, gas exchange, photosynthesis, and $\mathrm{ABA}$ content under salt stress.

\section{Materials and Methods}

2.1. Plant Material and Experiment Description. This investigation was conducted in Egypt $\left(30^{\circ} 06^{\prime} \mathrm{N}\right.$ and $\left.31^{\circ} 25^{\prime} \mathrm{E}\right)$ during the winter of 2020. Three wheat cultivars (Triticumn aestivum L.) (Sakha69, Giza168, and Sakha8) were used in this investigation. The grains were provided by the Egypt Agriculture Ministry. Homogeneous samples of wheat grain were sterilized by $0.01 \% \mathrm{HgCl}_{2}$ for 3 minutes and further washed in sterilized $\mathrm{H}_{2} \mathrm{O}$. The wheat grains of all cultivars were planted in pots ( 50 grains $/$ pot; $25 \mathrm{~cm}$ wide $\times 30 \mathrm{~cm}$ high) that were filled with $5 \mathrm{~kg}$ soil $(\operatorname{sand} /$ clay $=1: 2, \mathrm{v} / \mathrm{v})$. The experiment was conducted in a greenhouse with $19.2 / 30.1^{\circ} \mathrm{C}$ day/night temperature, $63 / 68 \%$ relative humidity, and a $16 \mathrm{~h}$ photoperiod. The seedlings were irrigated with tap water to field capacity and allowed to grow for 60 days. Hoagland nutrient solution (1/10 strength) was applied once a week. On day 21 from planting, phosphorus and nitrogen fertilizers were applied to the plants, based on the recommended doses of $35 \mathrm{~kg} \mathrm{P} \cdot \mathrm{ha}^{-1}$ (potassium dihydrogen phosphate) and $35 \mathrm{~kg}$ $\mathrm{N} \cdot h \mathrm{a}^{-1}$ (urea), respectively.

After eight weeks from planting (heading stage), the pots were divided into four $\mathrm{NaCl}$ treatments for each cultivar $(0 \mathrm{mM}, 40 \mathrm{mM}, 80 \mathrm{mM}$, and $160 \mathrm{mM})$. The treatment with $0 \mathrm{mM} \mathrm{NaCl}$ served as the control. During the experiment time, the stressed plants were irrigated with saltwater, and the unstressed plants (control) were irrigated by tap water to the field capacity. Sampling for different measurements was performed at two weeks after stress application (2WASA). Three replicates were taken to calculate the mean measurements of each treatment.
2.2. Growth Measurements. The growth parameters (shoot and root growth criteria and flag leaf area) of all the treated and untreated wheat plants were measured. The dry biomasses of the shoot, root, and flag leaf were measured by putting them into sacks and left to dry at $80^{\circ} \mathrm{C}$ in an oven until the weight became constant [13].

2.3. Relative Water Content Measurements. RWC of flag leaves was measured as maintained by the method of Schonfeld et al. [14]. Flag leaves were cut at the base by a scalpel following which the fresh weights (FW) were measured immediately. After that, the leaves were soaked for $24 \mathrm{hrs}$ in distilled $\mathrm{H}_{2} \mathrm{O}$ at room temperature. The turgid weights (TW) of flag leaves were determined after blotting them dry using tissue papers. The leaves were kept in an oven for $48 \mathrm{hrs}$ at $80^{\circ} \mathrm{C}$, and dry weights (DW) were measured. The LRWC of all the treatments were estimated as follows:

$$
\operatorname{LRWC}(\%)=\left(\frac{\mathrm{FW}-\mathrm{DW}}{\mathrm{TW}-\mathrm{DW}}\right) \times 100 \text {. }
$$

2.4. Estimation of Photosynthetic Pigments. $0.1 \mathrm{~g}$ FW of the flag leaf was ground in $80 \%$ cold acetone for $10 \mathrm{~min}$ centrifuged at $5000 \mathrm{rpm}$. The absorbance of the purified pigments samples was recorded at 470,646 , and $663 \mathrm{~nm}$ using a spectrophotometer against blank DMSO. Chlorophyll and carotenoid contents were calculated (mg g/DW) according to Lichtenthaler and Wellburn [15].

2.5. Estimation of Gas Exchange Parameters. Stomatal conductance (Gs), transpiration rate (Tr), and leaf net photosynthetic rate $(\mathrm{Pn})$ were estimated for photosynthetic gas exchange criteria of flag leaf between 9:00 and 10:00 am using an LCA-4 portable gas exchange system (Analytical Development Company Ltd, England). Determinations were carried out with a leaf area of $5.32 \mathrm{~cm}^{2}$, leaf chamber $\mathrm{CO}^{2}$ concentration of $370 \mathrm{ppm}$ at PPFD of $1800 \mathrm{mmol}$ photons/ $\mathrm{m}^{2} / \mathrm{s}$, and chamber temperature of $30^{\circ} \mathrm{C}$.

2.6. Stomatal Aperture Area Measurement. Stomatal aperture area (SAA) was evaluated during the selected times for the measurement of gas exchange parameters, according to the method described by Rodriguez and Davies [16]. The epidermis of the upper surface was separated from the flag leaf by making a split at a right angle to the veins on the upper surface using a sharpened razor blade. Then, the epidermis was separated from the flag leaf. The epidermis was fixed in alcohol, and the stomatal aperture area was measured under the microscope by determining the width and the length of its aperture using an ocular micrometer.

2.7. Extraction, Purification, and Determination of Abscisic Acid $(A B A)$. Flag leaves were extracted in $80 \%(\mathrm{v} / \mathrm{v})$ aqueous methanol, and prepurification was done using two-dimensional HPLC according to the method prescribed by Xiong et al. [17]; aliquots $(20 \mu \mathrm{L})$ were injected into a Waters Model 
$\mu 6 \mathrm{k}$-Universal liquid with columns $(\mathrm{C} 18-3.9 \times 300 \mathrm{~mm}$ silica-based packing materials). The injector was Water 510 HPLC Pump (Waters 486 Tunable); the flow was $1 \mathrm{ml} / \mathrm{min}$, and the filtrate passed through a $0.45 \mu \mathrm{m}$ filter. The determination of the ABA level was conducted as described by Wan and Li [18].

2.8. Statistical Analysis. The factors of main effect (wheat cultivar and salt concentration) were analysed using the Statistical Package for the Social Sciences (SPSS) version 11.0 computer software package [19]. A two-tailed $p$ value $<0.05$ was statistically significant. The paired sample $t$-test was applied to contrast the means without as well as with $\mathrm{NaCl}$ treatment. A one-way variance analysis (ANOVA) was applied to detect the significant differences in all measured parameters of the three wheat cultivars' responses between various applications with a significance level of less than $5 \%$ $(p<0.05)$.

\section{Results}

3.1. Salinity Stress Influences on Wheat Growth. Notable reduction $(p<0.05)$ was observed in growth in terms of plant height, shoot FW and DW, flag leaf area, root length, and root FW and DW of wheat cultivars exposed to 40,80 , or $160 \mathrm{mM} \mathrm{NaCl}$ treatments (Table 1 ). Without $\mathrm{NaCl}$ addition, the highest and lowest plant height $(73.61 \pm 3.54$ and $69.36 \pm 3.24)$ was recorded with Sakha8 and Giza168, respectively. With $\mathrm{NaCl}$ addition, there was a remarkable decrease in plant height in all cultivars, although the magnitude differed among cultivars. The reduction was more massive with 160 than 40 or $80 \mathrm{mM} \mathrm{NaCl}$ applications. The decrease in the plant height was 8,13 , and $19 \%$ for Sakha69, by 10,16 , and $21 \%$ for Giza168, and by 17,21 , and $32 \%$ for Sakha8, with 40, 80, and $160 \mathrm{mM} \mathrm{NaCl}$, respectively.

The results showed that the shoot's fresh and dry weights were considerably decreased $(p<0.05)$ by the presence of salinity stress in relation to control values (Table 1 ). The decline was more obvious with a higher dose of salinity application $(160 \mathrm{mM} \mathrm{NaCl})$. Comparing the reduction in shoot $\mathrm{FW}$ under three $\mathrm{NaCl}$ treatments, the response of all wheat plants was different. However, the lowest reduction was observed in Sakha69 (32\%) followed by Giza168 (36\%), and the highest reduction was recorded in Sakha8 (51\%) as relative to controls. Moreover, the maximum reduction in the shoot DW was noticed in Sakha8 (53\%) followed by Giza168 (39\%), and the minimum decrease was recorded in Sakha69 (32\%) as compared to control.

Furthermore, in relation to control values, the supplement of $\mathrm{NaCl}$ also decreased the flag leaf area of all wheat cultivars. However, the degree of reduction varied among cultivars (Table 1). The flag leaf area was decreased by 13 and $31 \%$ for Sakha69, by 23 and 36\% for Giza168, and by 36 and $50 \%$ for Sakha8 cultivars with 80 and $160 \mathrm{mM} \mathrm{NaCl}$, respectively (Table 1$)$. The highest $(20.65 \pm 2.45)$ and lowest $(10.42 \pm 2.07)$ flag leaf areas occurred with Sakha8 at 0 and $160 \mathrm{mM} \mathrm{NaCl}$, respectively.
Under control conditions, Sakha8 had higher root length than Giza168 and Sakha69. On the other hand, there was a noticeable decline $(p<0.05)$ in root length in all cultivars under the stress condition of 80 or $160 \mathrm{mM} \mathrm{NaCl}$ (Table 1). Relative to controls, the salt treatments reduced the root length by 20 and $29 \%$ for Sakha 69 cultivar, by 25 and 39\% for Giza168, and by 33 and 50\% for Sakha 8 at 80 and $160 \mathrm{mM}$ $\mathrm{NaCl}$ treatments, respectively.

Without the $\mathrm{NaCl}$ supplement, the highest root $\mathrm{FW}$ and DW $(1.95 \pm 0.09$ and $1.46 \pm 0.16)$ were observed in Sakha8. On the other hand, with $\mathrm{NaCl}$ supplement, the root FW and DW of all wheat cultivars were reduced as shown in Table 1. The reduction was significant $(p<0.05)$ with a higher dose of $\mathrm{NaCl}$ treatment $(160 \mathrm{mM})$. The lowest reduction in the root FW was noticed in Sakha69 (34\%) followed by Giza168 (36\%), and the highest decrease was observed in Sakha8 (44\%) as compared to controls. Furthermore, the minimum reduction in the root DW was recorded in Sakha69 (32\%) followed by Giza168 (40\%), and the maximum decrease was observed in Sakha8 (51\%) as compared to their respective controls.

3.2. The Impact of Salinity Stress on the Leaf Relative Water Content. A considerable reduction $(p<0.05)$ was recorded in LRWC of wheat plants exposed to $\mathrm{NaCl}$ stress condition (Figure 1). At high $\mathrm{NaCl}$ concentrations ( 80 and $160 \mathrm{mM}$ ), Sakha69 had the lowest decrease in LRWC (10.6 and 13.3\%); the greatest decrease occurred with Sakha8 (22.4 and 30.5\%) followed by Giza168 (18.3, and 24.4\%) as compared to the control plants.

\subsection{Impact of Salinity Stress on Photosynthetic Pigments.} The photosynthetic pigments ( $\mathrm{Chl}$ a, $\mathrm{Chl} \mathrm{b}$, carotenoids, and total pigments) are significantly $(p<0.05)$ decreased in all cultivars when treated with $\mathrm{NaCl}$, although the degree of reduction was greater in Sakha8 than in Giza168 and Sakha69. For instance, the percent declines in $\mathrm{Chl}$ a and $\mathrm{Chl}$ b were highest in Sakha8 (49.3 and 50\%) than in Giza168 (40.2 and 40.9\%) and Sakha69 (25.9 and 31.2\%) at a higher dose of salinity application $(160 \mathrm{mM} \mathrm{NaCl})$ when compared with their respective controls (Figures 2(a) and 2(b)). Moreover, under the application of $80 \mathrm{mM} \mathrm{NaCl}$, the reduction of $\mathrm{Chl}$ a and $\mathrm{Chl} b$ was maximum in Sakha8 (36.5 and $43.9 \%)$, followed by Giza168 (28.1 and 21.5\%) and Sakha69 (17.8 and 21.1\%), respectively.

Furthermore, under control conditions, the highest carotenoids $(1.36 \pm 0.87)$ and total pigments $(6.42 \pm 1.25)$ were detected in Giza168. Under high levels of $\mathrm{NaCl}$ (80 and $160 \mathrm{mM}$ ), the lowest reduction in carotenoids content was observed in Sakha69 (19.1 and 27.4\%), followed by Giza168 (34.4 and 41.1\%) and Sakha8 (42, and 53.1\%), respectively, as compared with controls (Figure 2(c)). Additionally, the reduction in total pigments was more significant $(p<0.05)$ in Sakha8 (39.3, and 50.2\%) than in Gizal68 (30.5, and $40.8 \%$ ) and Sakha69 (18.9, and 27.3\%) with the application of 80 and $160 \mathrm{mM} \mathrm{NaCl}$, respectively (Figure 2(d)). 
TABLE 1: Impact of salinity concentrations on growth criteria (shoot and root) of wheat cultivars.

\begin{tabular}{|c|c|c|c|c|c|c|c|c|}
\hline \multirow[b]{2}{*}{$\begin{array}{l}\text { Wheat } \\
\text { cultivar }\end{array}$} & & \multirow{2}{*}{$\begin{array}{l}\mathrm{NaCl} \\
\text { concentration } \\
\text { Plant height } \\
(\mathrm{cm}) \\
\bar{x} \pm \mathrm{SD}\end{array}$} & \multicolumn{4}{|c|}{ Shoot growth parameters } & \multicolumn{2}{|c|}{ Root growth parameters } \\
\hline & & & $\begin{array}{l}\text { Shoot fresh } \\
\text { weight }(g)\end{array}$ & $\begin{array}{l}\text { Shoot dry } \\
\text { weight (g) }\end{array}$ & $\begin{array}{c}\text { Flag leaf area } \\
\left(\mathrm{cm}^{2}\right)\end{array}$ & $\begin{array}{l}\text { Root length } \\
(\mathrm{cm})\end{array}$ & $\begin{array}{l}\text { Root fresh } \\
\text { weight }(g)\end{array}$ & $\begin{array}{c}\text { Root dry } \\
\text { weight (g) }\end{array}$ \\
\hline \multirow{5}{*}{ Sakha69 } & & & & & & & & \\
\hline & $0 \mathrm{mM}$ & $72.15 \pm 3.31 \mathrm{a}$ & $14.43 \pm 2.14 \mathrm{a}$ & $6.28 \pm 1.04 a$ & $18.35 \pm 3.22 \mathrm{a}$ & $25.57 \pm 2.51 \mathrm{a}$ & $1.83 \pm 0.30 \mathrm{~b}$ & $1.34 \pm 0.19 \mathrm{a}$ \\
\hline & $40 \mathrm{mM}$ & $66.24 \pm 4.34 \mathrm{a}$ & $12.58 \pm 1.10 \mathrm{~b}$ & $5.33 \pm 1.23 a$ & $17.11 \pm 2.75 b$ & $23.18 \pm 2.74 \mathrm{ab}$ & $1.67 \pm 0.41 \mathrm{a}$ & $1.11=$ \\
\hline & $80 \mathrm{mM}$ & $62.74 \pm 2.13 b$ & $11.86 \pm 1.31 \mathrm{~b}$ & $4.78 \pm 0.87 b$ & $15.94 \pm 2.54 b$ & $20.36 \pm 1.57 b$ & $1.48 \pm 0.23 c$ & $0.07 \mathrm{~b}$ \\
\hline & $160 \mathrm{mM}$ & $58.46 \pm 4.56 \mathrm{a}$ & $9.80 \pm 1.25 b$ & $4.25 \pm 0.66 b$ & $12.61 \pm 3.14 \mathrm{a}$ & $18.23 \pm 2.23 \mathrm{a}$ & $1.34 \pm 0.14 \mathrm{c}$ & $0.90 \pm 0.05 b$ \\
\hline \multirow{4}{*}{ Giza168 } & $0 \mathrm{mM}$ & $69.36 \pm 3.24 b$ & $13.52 \pm 1.41 b$ & $5.31 \pm 1.32 \mathrm{a}$ & $17.66 \pm 2.65 \mathrm{ab}$ & $28.21 \pm 2.63 a$ & $1.87 \pm 0.09 b$ & $1.39 \pm 0.08 \mathrm{~b}$ \\
\hline & $40 \mathrm{mM}$ & $62.56 \pm 3.63 b$ & $11.30 \pm 2.13 \mathrm{a}$ & $4.26 \pm 1.05 \mathrm{a}$ & $15.57 \pm 3.68 \mathrm{a}$ & $24.56 \pm 1.63 b$ & $1.61 \pm 0.34 \mathrm{a}$ & $1.10 \pm 0.10 \mathrm{~b}$ \\
\hline & $80 \mathrm{mM}$ & $58.17 \pm 4.25 \mathrm{a}$ & $10.01 \pm 2.24 \mathrm{a}$ & $3.68 \pm 1.02 \mathrm{a}$ & $13.53 \pm 1.47 \mathrm{~b}$ & $21.25 \pm 2.71 \mathrm{ab}$ & $1.47 \pm 0.14 \mathrm{ab}$ & $0.92 \pm 0.21 \mathrm{a}$ \\
\hline & $160 \mathrm{mM}$ & $54.73 \pm 2.61 \mathrm{~b}$ & $8.59 \pm 2.11 \mathrm{a}$ & $3.23 \pm 0.64 b$ & $11.25 \pm 1.51 b$ & $17.31 \pm 2.35 \mathrm{a}$ & $1.24 \pm 0.08 \mathrm{~b}$ & $0.83 \pm 0.23 \mathrm{a}$ \\
\hline \multirow{4}{*}{ Sakha8 } & $0 \mathrm{mM}$ & $73.61 \pm 3.54 \mathrm{ab}$ & $15.55 \pm 1.31 \mathrm{a}$ & $6.57 \pm 1.03 a$ & $20.65 \pm 2.45 a$ & $30.47 \pm 2.93 \mathrm{ab}$ & $1.95 \pm 0.09 b$ & $1.46 \pm 0.16 \mathrm{a}$ \\
\hline & $40 \mathrm{mM}$ & $60.54 \pm 3.12 \mathrm{a}$ & $11.01 \pm 1.25 \mathrm{a}$ & $4.84 \pm 1.12 \mathrm{a}$ & $16.63 \pm 1.67 b$ & $24.19 \pm 2.03 \mathrm{a}$ & $1.54 \pm 0.24 \mathrm{a}$ & $1.07 \pm 0.20 \mathrm{a}$ \\
\hline & $80 \mathrm{mM}$ & $58.14 \pm 4.65 a$ & $9.98 \pm 1.03 b$ & $4.06 \pm 0.48 \mathrm{ab}$ & $13.22 \pm 2.40 \mathrm{a}$ & $20.56 \pm 2.73 a$ & $1.39 \pm 0.12 \mathrm{ab}$ & $0.90 \pm 0.13 b$ \\
\hline & $160 \mathrm{mM}$ & $50.26 \pm 3.20 \mathrm{ab}$ & $7.62 \pm 1.53 \mathrm{ab}$ & $3.11 \pm 0.42 \mathrm{ab}$ & $10.42 \pm 2.07 b$ & $15.11 \pm 1.75 b$ & $1.10 \pm 0.14 \mathrm{ab}$ & $0.71 \pm 0.06 \mathrm{~b}$ \\
\hline
\end{tabular}

Means and standard errors are demonstrated by error bars. Letters point out significant differences at $p<0.05$.

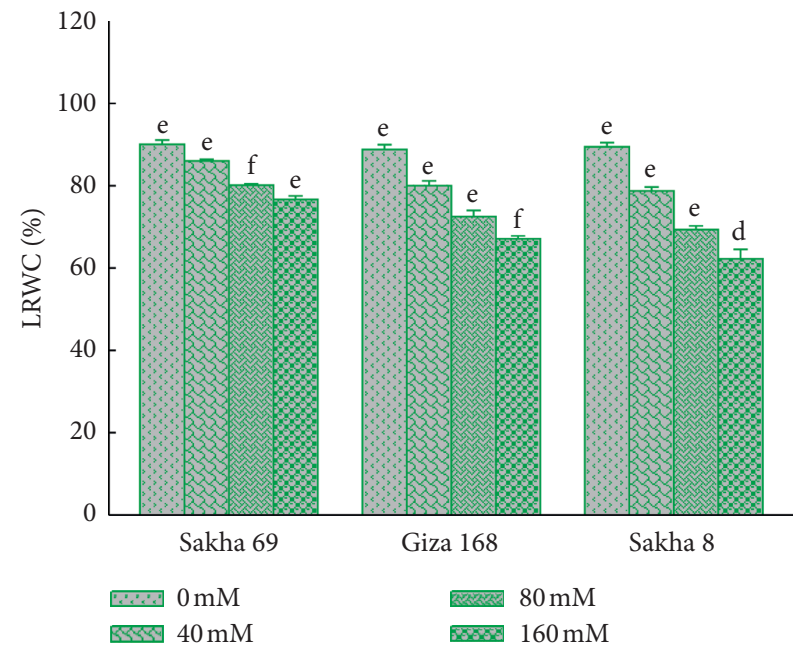

Figure 1: $\mathrm{NaCl}$ stress $(0,40,80$, and $160 \mathrm{mM})$ reduced the leaf relative water content (LRWC) of wheat cultivars. Each column symbolizes mean $\pm \mathrm{SE}(n=3)$. Means and standard errors are demonstrated by error bars. Letters point out significant differences at $p<0.05$.

3.4. Measurement Role of Stomatal Aperture Area and Gas Exchange Parameters for Salt Tolerance of Wheat Cultivars. Stomatal aperture area (SAA), stomatal conductance (Gs), transpiration rate $(\mathrm{Tr})$, and photosynthetic rate $(\mathrm{Pn})$ were appraised for all cultivars to evaluate their roles in wheat salt tolerance. SAA, Gs, $\mathrm{Tr}$, and $\mathrm{Pn}$ in NaCl-treated plants markedly varied between the three wheat cultivars (Figure 3). A significant reduction in SAA, Gs, Tr, and Pn was noticed for all wheat cultivars, although the extent of reduction was higher in Sakha8 than in Sakha69 and Giza168.

Salinity-stressed plants exhibited a noticeable lowering in SAA values as a result of 40,80 , and $160 \mathrm{mM} \mathrm{NaCl}$ treatments, as related to the control values (Figure 3(a)). $\mathrm{NaCl}$ stress caused a remarked decrease as the salinity levels increase. The maximum reduction was recorded in Sakha8
$(23.4,33.8$, and $45.9 \%)$ followed by Giza168 (18.4, 29.2, and $37.4 \%$ ), and the minimum reduction was detected in Sakha69 (11.2, 23.1, and 32.4\%) with 40, 80, and $160 \mathrm{mM}$ $\mathrm{NaCl}$ application concentrations, respectively.

A similar manner of results was investigated for the stomatal conductance (Gs) where it was significantly $(p<0.05)$ reduced by $24.5,38.2$, and $55.5 \%$ in Sakha8 under 40,80 , and $160 \mathrm{mM} \mathrm{NaCl}$ stress, respectively (Figure 3(b)). Moreover, the reduction in Gs was less in Sakha69 (13.1, 25.2 , and $35.4 \%$ ), whereas it was reduced in Giza168 by 17.5 , 28.4 , and $41.9 \%$, with 40,80 , and $160 \mathrm{mM} \mathrm{NaCl}$ treatments, respectively, as compared to the control.

Without $\mathrm{NaCl}$ addition, Giza168 had higher transpiration rate $(3.53 \pm 1.41)$ followed by Sakha8 $(3.46 \pm 1.27)$ and Sakha69 (3.34 \pm 1.16$)$. With $\mathrm{NaCl}$ addition, the degree of reduction was minimal in Sakha69 $(15.5,20.5$, and 28.9\%), whereas Tr was significantly decreased by $22.3,28.2$, and 36.8 in Giza168 and 26.5, 39.3 and 48.8\% in Sakha8 under 40, 80, and $160 \mathrm{mM} \mathrm{NaCl}$ salt, respectively, as related to control values (Figure 3(c)). Additionally, the current reduction in photosynthetic rate $(\mathrm{Pn})$ was lower in Sakha69 (15.3, 27.2, and $36.8 \%)$ than in Giza168 (24.9, 32.9, and 43.3\%) and Sakha8 (28.2, 39.3, and 53.5\%) with 40, 80, and $160 \mathrm{mM}$ $\mathrm{NaCl}$ concentrations, respectively, in comparison with their respective controls (Figure $3(\mathrm{~d})$ ). The highest and lowest Pn values (18.51 and 8.56) were noticed in Sakha 8 with 0 and $160 \mathrm{mM} \mathrm{NaCl}$ treatments, respectively.

3.5. Impact of Salinity Stress on ABA Level. As shown in Figure 4, in comparison with control values, the saline condition induced a remarkable enhance $(p<0.05)$ in the ABA levels in all cultivars' leaves. The ABA levels increased by $5 \%, 10 \%$, and $14 \%$ in Sakha $69 ; 7 \%, 12 \%$, and $22 \%$ in Giza168; and 15\%, 25\%, and 34\% in Sakha8 with 40, 80, and $160 \mathrm{mM}$ salt applications, respectively. The lowest $(0.18 \pm 0.09)$ and the highest values of ABA $(0.84 \pm 0.14)$ were observed with Sakha69 and Sakha 8 under $0 \mathrm{mM}$ and $160 \mathrm{mM} \mathrm{NaCl}$ treatments, respectively. 


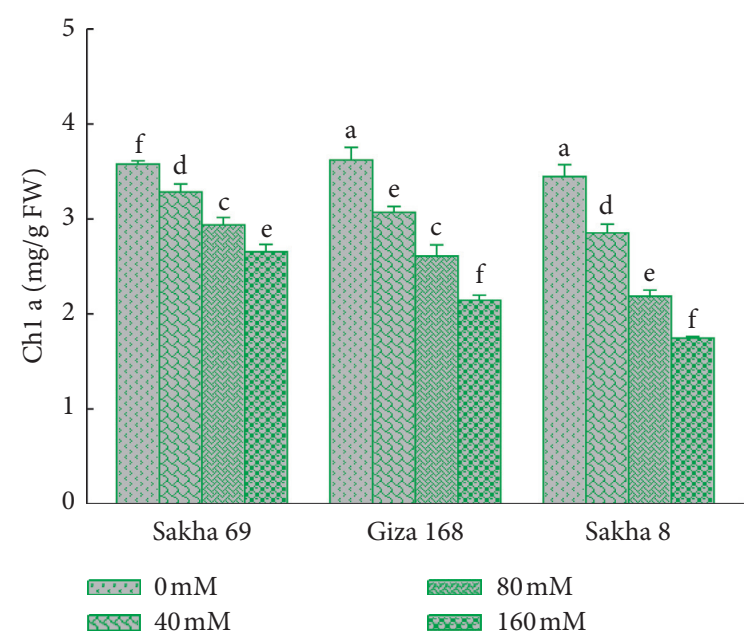

(a)

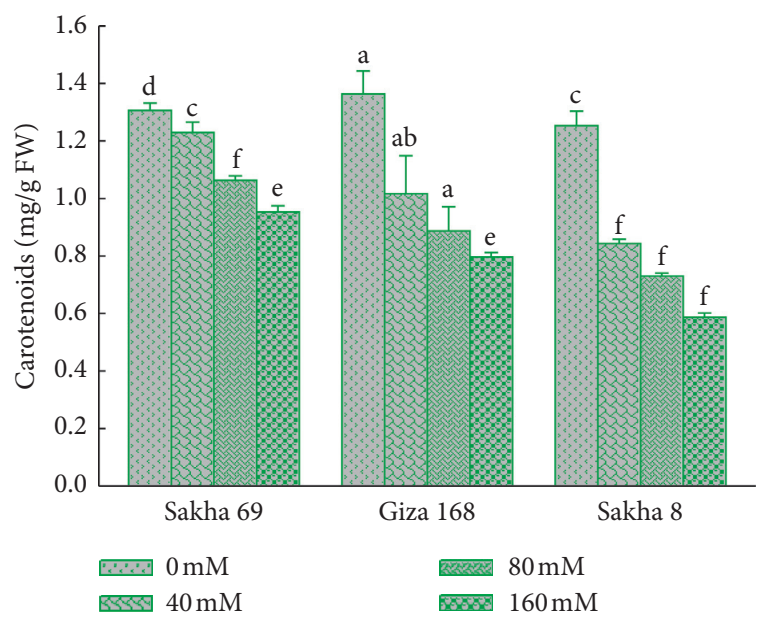

(c)

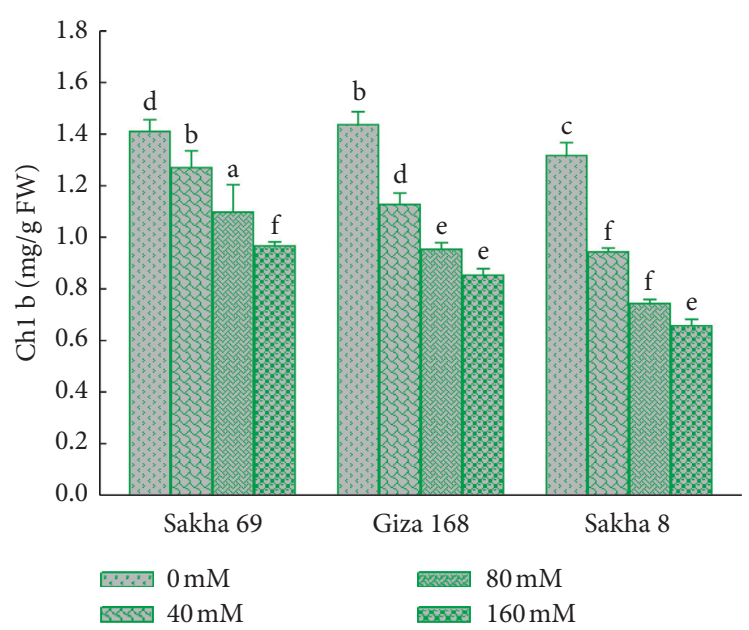

(b)

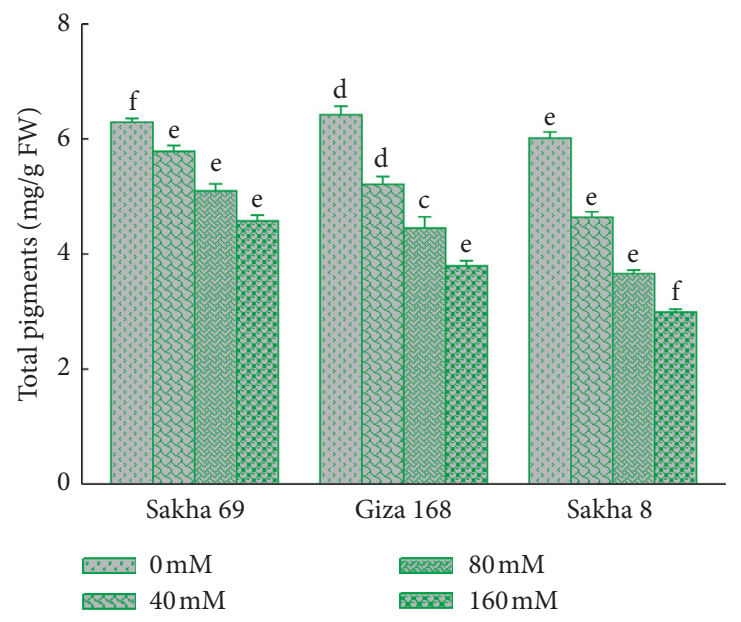

(d)

FIGURE 2: The impact of salt stress $(0,40,80,160 \mathrm{mM})$ on the photosynthetic pigments in flag leaf of wheat cultivars: (a) Chl a; (b) Chl b; (c) carotenoids; and (d) total pigments. Each column symbolizes mean \pm SE $(n=3)$. Means and standard errors are demonstrated by error bars. Letters point out significant differences at $p<0.05$.

\section{Discussion}

Plants deal with saline condition by tolerating or avoiding [7], and the ability of plants to be resistant to salinity stress differs according to the cultivars and species [20]. Moreover, the tolerant cultivars cultivation is realized as the most ultimate strategy to deal with the limitations of plant production in saline conditions [12]. In the current study, the growth parameters, water status, and photosynthetic characteristics were used to scan the salt tolerance in three wheat cultivars. Salinity stress induced a remarked reduction in the shoot and root growth performance of all wheat cultivars as the salt levels increased (Table 1). The effect was more obvious with the $160 \mathrm{mM} \mathrm{NaCl}$ level. The notable decreases were observed with Sakha8, which was the most influenced cultivar by saline conditions, followed by Giza168 and Sakha69 which was the most resistant cultivar to the $\mathrm{NaCl}$ salt application.
The response of plant growth to salinity stress varies among species and has been reported in many investigations $[1,2,5,21,22]$. In this consideration, Bacu et al. [7] demonstrated that an increase in salt concentration $(50,100$, and $200 \mathrm{mM} \mathrm{NaCl}$ ) induced a significant decrease in the growth criteria (shoot, root, and leaf length) of five wheat cultivars. Moreover, Mohamed et al. [3] reported that the 100 and $200 \mathrm{mM} \mathrm{NaCl}$ concentrations markedly decreased the biomass of shoot and root of 10 cultivars of rapeseed. Salinity conditions are supposed to adversely influence the absorption of water by plant roots, causing ion toxicity, ionic/nutritional imbalance, and/or an osmotic stress [23]. These damage effects induced by salt stress suppress the wheat shoot and root growth and therefore negatively affect FW and DW. Moreover, there was a progressive reduction in the wheat's FW and DW weights with increasing $\mathrm{NaCl}$ level, which was compatible with previous studies $[1,22]$. The minimum decrease in the FW and DW in Sakha69 cultivar 


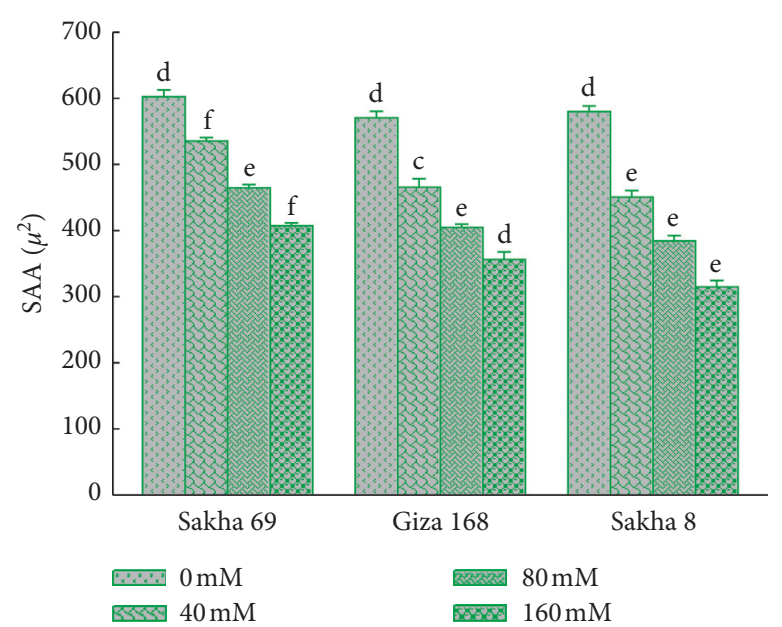

(a)

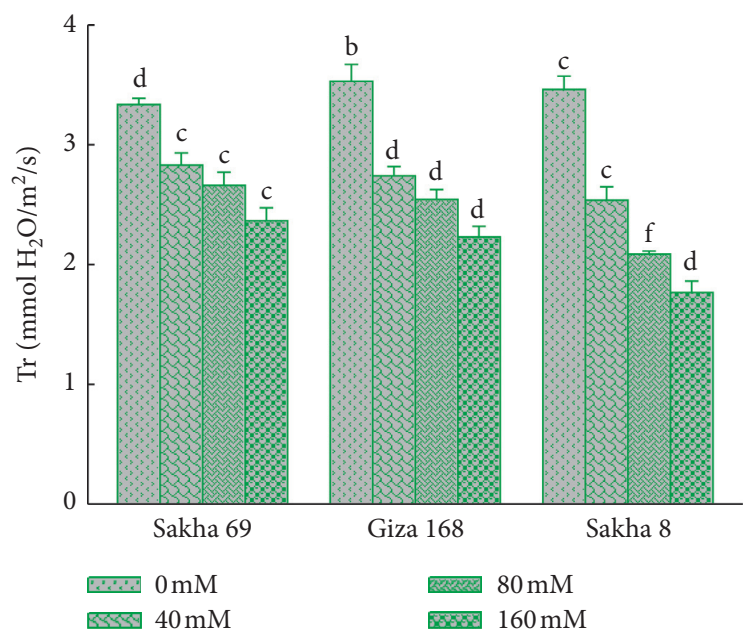

(c)

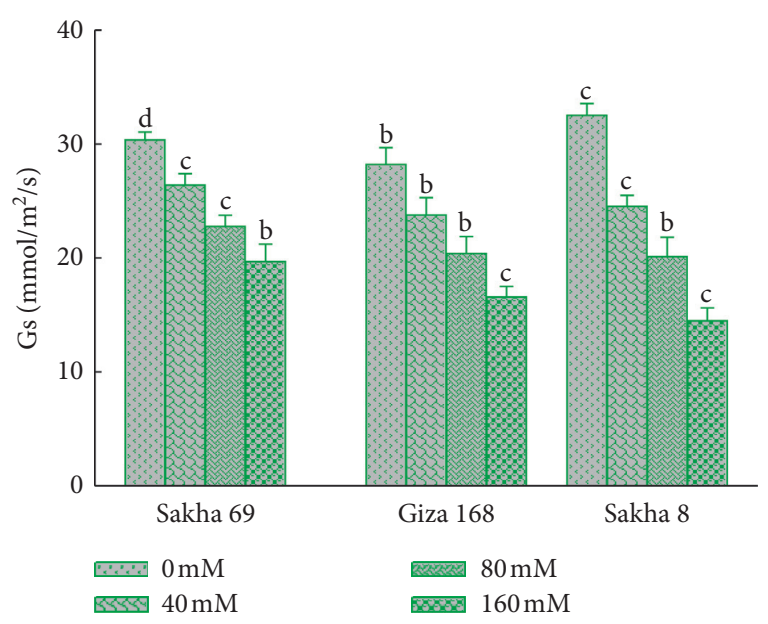

(b)

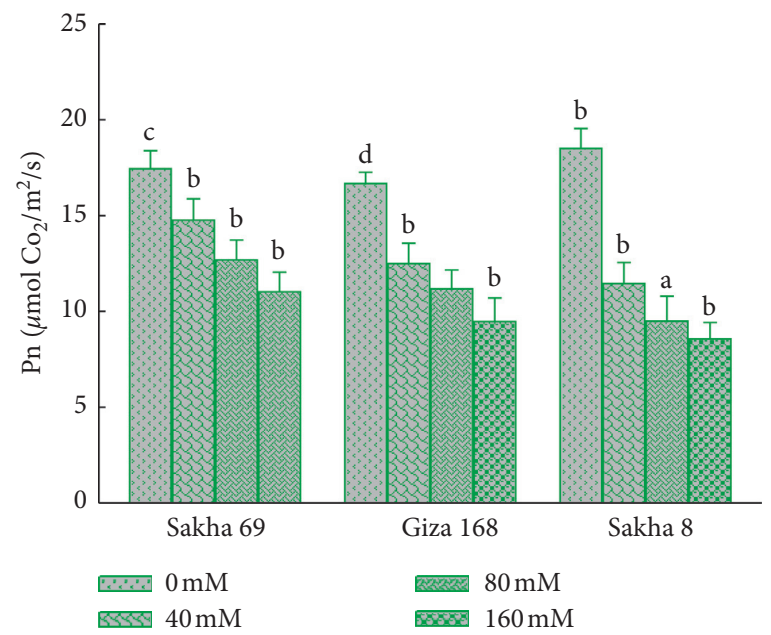

(d)

Figure 3: Gas exchange parameters and stomatal aperture area responses to salinity (0,40, 80, and $160 \mathrm{Mm})$ of wheat cultivars: (a) stomata aperture area (SAA); (b) stomatal conductance (Gs); (c) transpiration rate (Tr); (d) photosynthetic rate (Pn). Each column symbolizes mean \pm SE $(n=3)$. Means and standard errors are demonstrated by error bars. Letters point out significant differences at $p<0.05$.

might be due to the extraeffective detoxification mechanism, including the antioxidant defence mechanisms. The growth reduction was also noticed in both the plant height and root length. These results were the same as the results of Ahmed et al. [1] with lettuce plants and Elhakem [21] with maize plants. In this regard, Bacu et al. [7] reported that the chemical potential of the salinity conditions initially establishes a water potential imbalance between the symplast and apoplast which causes turgor reduction that can lead to a decrease in the plant growth. The present study showed that the impact of salinity is not demonstrated only in the region subjected to saline conditions (the roots) but also in the shoot system. According to Annunziata et al. [6], plants act as an incorporated system in which the dispersed metabolic stress-caused signals alter even the metabolism of plant areas that are not under any stress conditions. Moreover, various parts of the plant's root system could act as physiologically independent units that respond to environmental signals in various ways and maintain their own proficiency to provide shoots with nutrients, water, as well as photosynthetic assimilates [7].

RWC is a basic criterion that may be applied to screen the plant's tolerance to saline conditions and is a key marker in environmental stress studies, especially salinity stress [3]. In addition, almost all the cells' physiological and biochemical processes such as cell enlargement, cell division, photosynthesis, stomata opening, assimilates transportation, and mineral nutrition depend on the water status of the cells; thus, water content reduction may have a negative impact on the plant growth and yield [24]. According to Slabbert and Krüger [25], RWC may be maintained in the plant cells and tissues, allowing metabolic activity resumption by osmotic adjustments and other physiological attributes related to salt stress tolerance. Furthermore, saline condition has destructive influences on the water absorption due to the osmotic effect. Salt accumulation in the root area reduces the osmotic potential, resulting in a water potential reduction and decrease in the available water amount to be dispersed to 


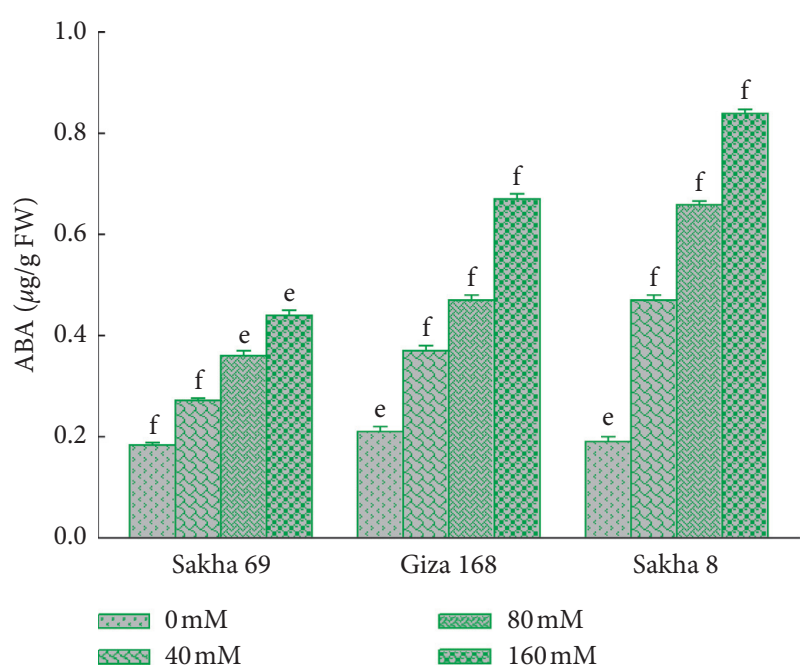

FIGURE 4: Response of ABA ( $\mu \mathrm{g} / \mathrm{g}$ FW) of wheat cultivars flag leaves to salinity stress at 2 WASA. Each column symbolizes mean \pm SE $(n=3)$. The mean standard errors are demonstrated by error bars. Letters point out significant differences $(p<0.05)$.

the plant root system [1]. In this respect, Acosta-Motos et al. [26] reported that plants could stabilize their water potential by water loss, inducing a reduction in osmotic potential. Consequently, plants could adapt to saline conditions by lowering their water content.

The current study showed that salinity stress led to an observable decrease in the LRWC of all cultivars as the salt levels increased (Figure 1). These findings are incompatible with those obtained in previous studies [1, 3, 24, 27]. When compared with Giza168 and Sakha8, Sakha69 cultivar had a high LRWC; this means that it had a higher capability for water uptake from the soil and kept higher plant-water status as a result of the plant's capability to maintain better osmotic and water potential in roots and leaves tissues under saline conditions. This was reflected in further consideration that the magnitude of reduction in the leaf area was more noticeable in Giza168 and Sakha8 (Table 1). In addition, the reduction in all shoot and root growth parameters of Giza168 and Sakha8 cultivars correlated with the LRWC reduction. These data were proportionate with those noticed by Mohamed et al. [3]. Moreover, Al Kharusi et al. [27] reported that cell expansion is a purpose of water absorption, and the cell wall extension and leaf area conservation are a result of the cell expansion that is successively correlated with the water status of the plants grown in saline soils.

Pigment contents are a useful photosynthetic activity indicator when plants grown under various stressful environments [1, 7]. In the current investigation, salt stress induced a remarkable reduction in photosynthetic pigment contents in all wheat cultivars as $\mathrm{NaCl}$ stress increased (Figure 2). The impact of salt stress on pigment contents was more observable with Giza168 and Sakha8 cultivars. However, Sakha69 was resistant to $\mathrm{NaCl}$ saltand maintained the pigment contents to appropriate levels. In this regard, $\mathrm{Ma}$ et al. [28] reported that saline conditions caused pigment degradation and leaf burning in salt-sensitive species. A suppressed effect of salinity on photosynthetic pigments has been reported in many investigations $[3,5,7]$.

The obtained results revealed negative influences of salt stress on the stomatal conductance (Gs), net photosynthetic rate $(\mathrm{Pn})$, and transpiration rate $(\mathrm{Tr})$ of wheat cultivars (Figure 3). Earlier investigations have reported that salt stress led to a massive decrease in the photosynthetic gas exchange parameters [28, 29]. Moreover, the data showed that the capacity of photosynthesis process is reduced due to osmotic stress and, as a consequence, partial closure of the stomata. Severe saline conditions resulted in a massive decrease in the parameters of photosynthetic gas exchange in the salt-sensitive cultivar, Sakha8, compared with the salttolerant cultivar, Sakha69. These results were consistent with Nounjan et al. [30] who stated that photosynthetic process protection from injury-maintained photosynthesis and so salinity tolerance in rice cultivars.

Stomata are greatly sensitive to abiotic stresses, and their distribution and number may alter [3]. Furthermore, water uptake and transpiration are, to a certain extent, monitored by the plant through the stomatal opening regulation. In the current study, $\mathrm{NaCl}$-stressed wheat plants displayed a high decrease in SAA. However, the stomatal conductance was enhanced as salinity increased (Figure 3). These findings were proportionate with Waqas et al. [31] who found that SAA was decreased on the lower and upper leaves' surfaces of quinoa plants in response to salinity. SAA was investigated to be lower in the salt-tolerant cultivar, Sakha69, than in the sensitive one, Sakha8 (Figure 3). In this regard, Zörb et al. [32] reported that salinity conditions could lead to a massive reduction in the epidermal cells and subsidiary cells in a sensitive maize cultivar during the development of stomata [32]. Moreover, Mohamed et al. [3] demonstrated that salinity decreased the lengths and widths of the epidermal cells. Our results showed that salinity stress caused a remarked reduction in the LRWC and SAA in the Sakha8 salt-sensitive cultivar. This variation resulted in a decrease in $\mathrm{Tr}, \mathrm{Pn}$, and Gs values. These findings agreed with those obtained by Júnior et al. [29] with banana cultivars. In another study, Mohamed et al. [3] found that salinity stress (100 and $200 \mathrm{mM} \mathrm{NaCl}$ ) had an injurious impact on the Tr, Gs, and Pn of 10 rapeseed cultivars, and SAA was recognized to be higher in salt-tolerant than in salt-sensitive cultivars. Furthermore, stomatal closure has massive impacts on photosynthesis, $\mathrm{CO}_{2}$ uptake, transpiration, and uptake of water, and these impact improvements in the salt-sensitive cultivars contributed to the sensitivity of salt stress. In this consideration, Acosta-Motos et al. [26] reported that cultivar-specific anatomical characteristics, such as greater SAA (open stomata), contribute in a high potential of water that contributed to the metabolic activity through osmotic adjustment during growth under stress conditions and so contributed to higher tolerance of salinity. In the salt-tolerant cultivar, higher SAA induced greater Tr, Pn, and Gs values than in the sensitive one. These results were compatible with those obtained by Júnior et al. [29].

Furthermore, the SAA reduction caused by salt stress could be due to an increase in the ABA biosynthesis in flag leaves of all wheat cultivars (Figure 4). This phytohormone 
triggers stomatal closure, thereby increasing plant turgor pressure. In this consideration, Polash et al. [33] stated that $\mathrm{NaCl}$ stress rapidly leads to disturbance in stomatal behaviour because of the interruption of water status and increases the ABA local synthesis in plant roots and at once moved to the leaves via xylem. These data were harmonious with the finding of Yang et al. [34] with sweet sorghum plant, Boussora et al. [35] and Zuo et al. [36] with barley plant. In another study, Chen et al. [8] reported that ABA may induce the $\mathrm{Ca}^{2+}$ channel opening that permits calcium ions to mediate the closure of stomata pores. In addition, calcium ion-mediated signals might be decoded by many $\mathrm{Ca}^{2+}$ sensors, including $\mathrm{Ca}^{2+}$-dependent protein kinase that might activate and phosphorylate the slow-type anion efflux channels, which can be implicated in the reduction of leaf water loss and closure of stomata [37].

\section{Conclusion}

The findings demonstrated in this investigation revealed that the wheat plants can tolerate salt stress by better conservation of water status of the whole plant, which may maintain relatively better availability of water within the plant tissue as observed in the salt-tolerant cultivar, Sakha69, compared with the salt-sensitive, Sakha8. In conclusion, based on growth rate parameters, LRWC, gas exchange parameters, pigment contents, and $\mathrm{ABA}$ level, wheat cultivar, Sakha8, is salt-sensitive (growth, LRWC, SAA, gas exchange parameters, pigments reduced, and higher $A B A$ ), Giza168 is medium-tolerant (growth, LRWC, SAA, gas exchange parameters, pigments partially injured and medium ABA), and Sakha69 is salt-tolerant (growth and pigments partially injured, higher LRWC, greater SAA, gas exchange parameters increased, and lower $A B A$ ). Taken together, most of the evaluated parameters were less influenced under salt-tolerant Sakha69 cultivar compared with the medium-tolerant Giza168 and the salt-sensitive Sakha8, which suggest the salinity impact is better neutralized in the tolerant wheat cultivars. Besides, this investigation demonstrates proof that growth, photosynthetic gas exchange parameters, stomata anatomical characteristics, and ABA level had a significant role in the salinity tolerance of wheat cultivars.

\section{Data Availability}

Raw data are available from the corresponding author upon request.

\section{Conflicts of Interest}

The author declares no conflicts of interest.

\section{Acknowledgments}

The author would like to thank the Deanship of Scientific Research at Prince Sattam Bin Abdulaziz University, Saudi Arabia, for their support.

\section{References}

[1] S. Ahmed, S. Ahmed, S. K. Roy, S. H. Woo, K. D. Sonawane, and A. M. Shohael, "Effect of salinity on the morphological, physiological and biochemical properties of lettuce (lactuca sativa L.) in Bangladesh," Open Agriculture, vol. 4, no. 1, pp. 361-373, 2019.

[2] A. A. Elshafei, S. A. E.-A. Afiah, A. A. Al-Doss, and E. I. Ibrahim, "Morphological variability and genetic diversity of wheat genotypes grown on saline soil and identification of new promising molecular markers associated with salinity tolerance," Journal of Plant Interactions, vol. 14, no. 1, pp. 564-571, 2019.

[3] I. A. A. Mohamed, N. Shalby, C. Bai et al., "Stomatal and photosynthetic traits are associated with investigating sodium chloride tolerance of Brassica napus L. cultivars," Plants, vol. 9, no. 62, 2020.

[4] R. A. Agami, H. A. Ghramh, and M. Hasheem, "Seed inoculation with Azospirillum lipoferum alleviates the adverse effects of drought stress on wheat plants," Journal of Applied Botany and Food Quality, vol. 90, no. 1, pp. 165-173, 2017.

[5] S. El-Hendawy, N. Al-Suhaibani1, M. Alotaibi et al., "Estimating growth and photosynthetic properties of wheat grown in simulated saline field conditions using hyperspectral reflectance sensing and multivariate analysis," Scientific Reports, vol. 9, no. 1, pp. 1-15, 2019.

[6] M. G. Annunziata, L. F. Ciarmiello, P. Woodrow et al., "Durum wheat roots adapt to salinity by remodeling the cellular content of nitrogen metabolites and sucrose," Frontiers in Plant Science, vol. 7, no. 1-16, 2017.

[7] A. Bacu, V. Ibro, and M. Nushi, "Compared salt tolerance of five local wheat (Triticum aestivum L.) cultivars of Albania based on morphology, pigment synthesis and glutathione content," The EuroBiotech Journal, vol. 4, no. 1, pp. 42-52, 2020.

[8] K. Chen, G. J. Li, R. A. Bressan, C. P. Song, J. K. Zhu, and Y. Zhao, "Abscisic acid dynamics, signaling, and functions in plants," Journal of Integrative Plant Biology, vol. 62, no. 1, pp. 25-54, 2020.

[9] R. Waadt, K. Hitomi, N. Nishimura et al., "FRET-based reporters for the direct visualization of abscisic acid concentration changes and distribution in arabidopsis," eLife, vol. 3, Article ID e01739, 2014.

[10] N. Loutfy, Y. Sakuma, D. K. Gupta, and M. Inouhe, "Modifications of water status, growth rate and antioxidant system in two wheat cultivars as affected by salinity stress and salicylic acid," Journal of Plant Research, vol. 133, no. 4, pp. 549-570, 2020.

[11] FAO, Cereal Supply and Demand Brief, FAO, Rome, Italy, 2020, http://www.fao.org/worldfoodsituation/csdb/en/.

[12] B. C. Oyiga, R. C. Sharma, J. Shen et al., "Identification and characterization of salt tolerance of wheat germplasm using a multivariable screening approach," Journal of Agronomy and Crop Science, vol. 202, no. 6, pp. 472-485, 2016.

[13] E. Carpýcý, N. Celýk, and G. Bayram, "Effects of salt stress on germination of some maize (Zea mays L.) cultivars," African Journal of Biotechnology, vol. 8, no. 19, pp. 4918-4922, 2009.

[14] M. A. Schonfeld, R. C. Johnson, B. F. Carver, and D. W. Mornhinweg, "Water relations in winter wheat as drought resistance indicators," Crop Science, vol. 28, no. 3, pp. 526-531, 1988.

[15] H. K. Lichtenthaler and A. R. Wellburn, "Determinations of total carotenoids and chlorophylls a and b of leaf extracts in different solvents," Biochemical Society Transactions, vol. 11, no. 5, pp. 591-592, 1983. 
[16] J. L. Rodriguez and W. J. Davies, "The effects of temperature and ABA on stomata of Zea mays L," Journal of Experimental Botany, vol. 33, no. 5, pp. 977-987, 1982.

[17] L. Xiong, M. Ishitani, H. Lee, and J.-K. Zhu, “The arabidopsis LOS5/ABA3 locus encodes a molybdenum cofactor sulfurase and modulates cold stress- and osmotic stress-responsive gene expression," The Plant Cell, vol. 13, no. 9, pp. 2063-2083, 2001.

[18] X.-R. Wan and L. Li, "Regulation of ABA level and waterstress tolerance of arabidopsis by ectopic expression of a peanut 9-cis-epoxycarotenoid dioxygenase gene," Biochemical and Biophysical Research Communications, vol. 347, no. 4, pp. 1030-1038, 2006.

[19] W. W. Daniel, Biostatistics: A Foundation for Analysis in the Health Science, John Wiley and Sons, New York, NY, USA, 6th edition, 1995.

[20] R. Shokri-Gharelo and P. M. Noparvar, "Molecular response of canola to salt stress: insights on tolerance mechanisms," PeerJ, vol. 6, Article ID e4822, 2018.

[21] A. H. Elhakem, "Mitigation of the salinity influences on maize (zea mays 1.) productivity by exogenous applications of glycine betaine," Journal of Stress Physiology and Biochemistry, vol. 15, no. 3, pp. 21-28, 2019.

[22] H. Yan, S. S. Shah, W. Zhao, and F. Liu, "Variations in water relations, stomatal characteristics, and plant growth between quinoa and pea under salt-stress conditions," Pakistan Journal of Botany, vol. 52, no. 1, 2020.

[23] S. V. Isayenkov and F. J. M. Maathuis, "Plant salinity stress: many unanswered questions remain," Frontiers in Plant Science, vol. 10, no. 80, pp. 1-11, 2019.

[24] M. Ansari, F. Shekari, M. H. Mohammadi, G. Végváric, and B. Biró, "Effect of irrigation with saline water on ion homeostasis and forage dry yield in alfalfa ecotypes application of high salty water for alfalfa plants irrigation," Desert, vol. 24, no. 1, pp. 1-12, 2019.

[25] M. M. Slabbert and G. H. J. Krüger, “Antioxidant enzyme activity, proline accumulation, leaf area and cell membrane stability in water stressed Amaranthus leaves," South African Journal of Botany, vol. 95, pp. 123-128, 2014.

[26] J. Acosta-Motos, M. Ortuño, A. Bernal-Vicente, P. DiazVivancos, M. Sanchez-Blanco, and J. Hernandez, "Plant responses to salt stress: adaptive mechanisms," Agronomy, vol. 7, no. 1, pp. 18-55, 2017.

[27] L. Al Kharusi, R. Sunkar, R. Al-Yahyai, and M. W. Yaish, "Comparative water relations of two contrasting date palm genotypes under salinity," International Journal of Agronomy, vol. 2019, Article ID 4262013, 16 pages, 2019.

[28] N. Ma, C. Hu, L. Wan, Q. Hu, J. Xiong, and C. Zhang, "Strigolactones improve plant growth, photosynthesis, and alleviate oxidative stress under salinity in rapeseed (Brassica napus L.) by regulating gene expression," Frontiers in Plant Science, vol. 8, no. 1671, pp. 1-15, 2017.

[29] E. B. S. Júnior, E. F. Coelho, K. S. Gonçalves, and J. L. Cruz, "Physiological and vegetative behavior of banana cultivars under irrigation water salinity," Revista Brasileira de Engenharia Agrícola e Ambiental, vol. 24, no. 2, pp. 82-88, 2019.

[30] N. Nounjan, V. Charoensawan, P. Chansongkrow et al., "High performance of photosynthesis and osmotic adjustment are associated with salt tolerance ability in rice carrying drought tolerance QTL: physiological and co-expression network analysis," Frontiers in Plant Science, vol. 91135 pages, 2018.

[31] M. Waqas, C. Yaning, H. Iqbal, M. Shareef, H. Rehman, and Y. Yang, "Paclobutrazol improves salt tolerance in quinoa: beyond the stomatal and biochemical interventions," Journal of Agronomy and Crop Science, vol. 203, no. 4, pp. 315-322, 2017.

[32] C. Zörb, K. H. Mühling, U. Kutschera, and C.-M. Geilfus, "Salinity stiffens the epidermal cell walls of salt-stressed maize leaves: is the epidermis growth-restricting?" PLoS One, vol. 10, no. 3, Article ID e0118406, 2015.

[33] M. A. S. Polash, M. A. Sakil, and M. A. Hossain, "Plants responses and their physiological and biochemical defense mechanisms against salinity: a review," Tropical Plant Research, vol. 6, no. 2, pp. 250-274, 2019.

[34] Z. Yang, J.-L. Li, L.-N. Liu, Q. Xie, and N. Sui, "Photosynthetic regulation under salt stress and salt-tolerance mechanism of sweet sorghum," Frontiers in Plant Science, vol. 10, p. 1722, 2020.

[35] F. Boussora, M. Allam, F. Guasmi et al., "Spike developmental stages and ABA role in spikelet primordia abortion contribute to the final yield in barley (hordeum vulgare L.)," Botanical Studies, vol. 60, no. 1, pp. 13-24, 2019.

[36] Z. Zuo, J. Guo, C. Xin et al., "Salt acclimation induced salt tolerance in wild-type and abscisic acid-deficient mutant barley," Plant, Soil and Environment, vol. 65, no. 10, pp. 516-521, 2019.

[37] B. Brandt, D. E. Brodsky, S. Xue et al., "Reconstitution of abscisic acid activation of SLAC1 anion channel by CPK6 and OST1 kinases and branched ABI1 PP2C phosphatase action," Proceedings of the National Academy of Sciences, vol. 109, no. 26, pp. 10593-10598, 2012. 